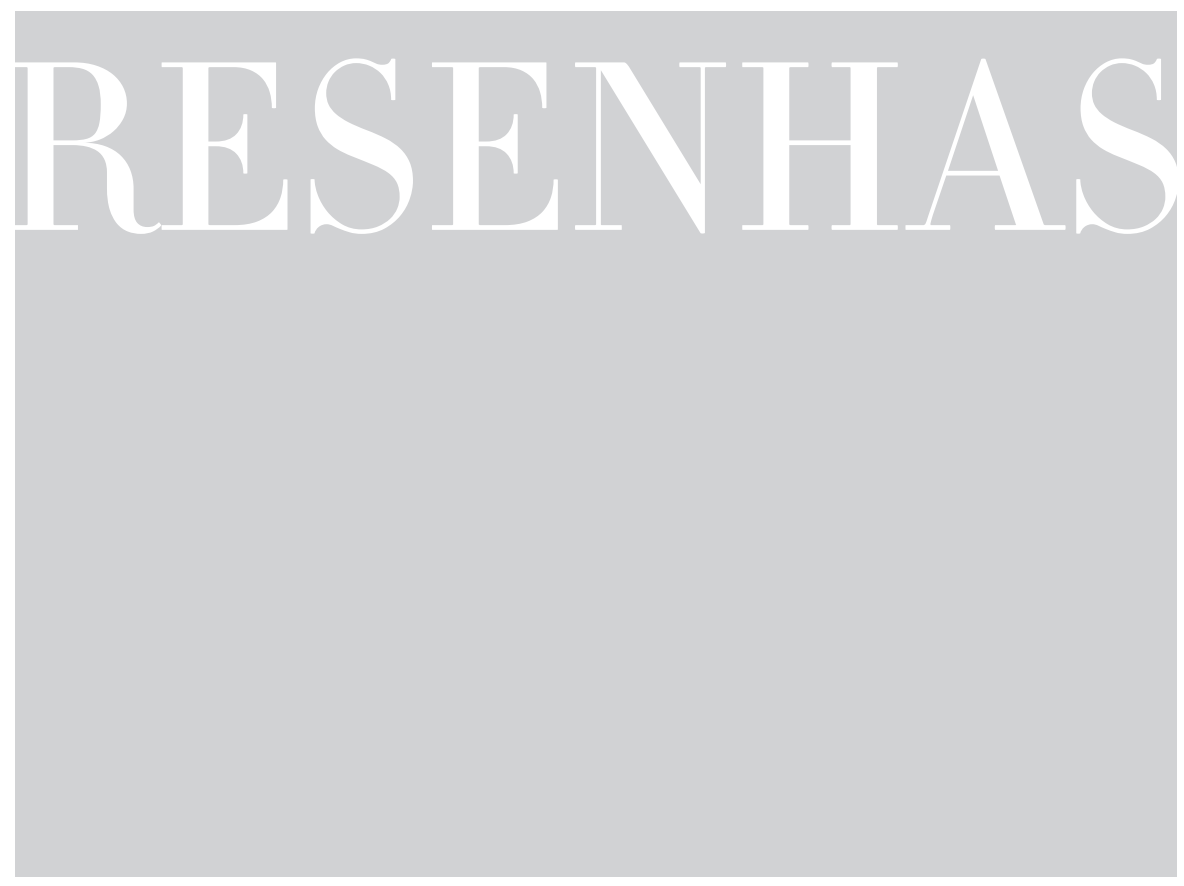

\title{
TEORIA QUEER E AS DIFERENÇAS
}

http://dx.doi.org/10.1590/198053143041

MISKOLCI, Richard. Teoria Queer: um aprendizado pelas diferenças.

Richard Miskolci é professor associado do Programa de Pós-Graduação em Sociologia da Universidade Federal de São Carlos, destacando-se em pesquisas que envolvem sexualidade, gênero e raça/etnia.

O livro Teoria Queer: um aprendizado pelas diferenças é uma revisão e ampliação de sua aula magna realizada na abertura do curso de Educação para a Diversidade e Cidadania, no centro de convenções da Universidade Federal de Ouro Preto - Ufop -, em 2010. A obra é composta por uma introdução e três capítulos, além de um anexo com o texto "A guerra declarada contra o menino afeminado”, em que Giancarlo Cornejo, um sociólogo peruano que realizava doutorado em Retórica na Universidade de Califórnia, Berkeley, relata sua experiência escolar.

Na introdução, o autor narra com extrema sensibilidade e reflexividade suas memórias dos tempos de escola, na época do regime militar, já refletindo sobre os gêneros, as masculinidades e questões de raça. Há um paralelo entre o ambiente escolar e a sociedade normalizadora e violenta, em que havia um culto à ordem, à disciplina e à autoridade, bem como uma associação entre o regime militar e a masculinidade hegemônica de violência. Assim, "um homem de verdade, hoje percebo, é o que impunha seu poder aos outros e a si mesmo à custa de sua própria afetividade" (MISKOLCI, 2012, p. 10). 
A partir do entendimento de que a educação ajuda na construção de homens e mulheres "ideais", o autor se inspira na teoria queer e proporciona um conjunto de reflexões para um novo olhar para a educação, buscando versar sobre as possibilidades de uma educação não normalizadora ou compulsória, mas focada na experiência de aprender: "vejo o aprendizado como algo que se constrói incessantemente em um diálogo com o que nos causa estranheza, ou seja, no contato com as diferenças” (MISKOLCI, 2012, p. 12).

No primeiro capítulo, "Origens históricas da teoria queer", ocorre um resgate histórico das origens dessa teoria, que teve início na década de 1960, estando associada aos novos movimentos sociais e à contracultura. Tais movimentos enfatizavam o privado como político e que as desigualdades iam além da esfera econômica e, em alguns casos, focavam o corpo, a sexualidade e o desejo. Essa teoria se fortaleceu nos anos 1980 com a epidemia de Aids nos Estados Unidos, que mostrou os valores conservadores daquela sociedade, mas também surgiram resistências como o Queer Nation:

A ideia por trás do Queer Nation era a de que parte da nação foi rejeitada, foi humilhada, considerada abjeta, motivo de desprezo e nojo, medo de contaminação. É assim que surge o queer, como reação e resistência a um novo momento biopolítico instaurado pela Aids (MISKOLCI, 2012, p. 24)

Nesse contexto, surge o novo movimento queer refletindo a respeito da heteronormatividade, pela qual gays e lésbicas normalizados são aceitos, enquanto aqueles que fogem à norma são considerados abjetos, havendo uma crítica aos movimentos sociais que se pautam nas políticas de identidade. Dessa maneira, existe uma receptividade com aqueles deslocados do movimento homossexual, como travestis, transexuais, não brancos, que não eram considerados dignos para integrarem o movimento. Essa nova política destaca-se por chamar atenção para as normas que criam o sujeito buscando desconstruir normas e convenções culturais, em uma perspectiva foucaultiana, salientando, ainda, o binário hétero-homo como uma construção histórica que deve ser repensada e analisada.

Torna-se relevante considerar também uma ampliação do conceito de gênero, que antes era entendido como sinônimo de mulheres, começando, com a teoria queer, a ser compreendido como elemento relacionado às normas e algo cultural que está presente tanto em homens como em mulheres. Evidencia-se uma sofisticação do feminismo, ampliando seu alcance para além das mulheres. Tal ampliação também pode ser ressaltada pelo argumento de que "não é apenas descobrir a forma correta de chamar alguém, mas, antes questionar esse processo de classificação que gera o xingamento" (MISKOLCI, 2012, p. 32). Pensando 
no campo da educação diretamente, é possível também questionar um currículo oculto marcado pela heterossexualidade compulsória, que pode ser construída por um processo de educação heteronormativo.

No âmbito teórico, o autor destaca os seguintes livros trazendo essa nova visão epistemológica para os estudos queer: Problemas de gênero, de Judith Butler; One hundred years of homosexuality (Cem anos de homossexualidade), de David M. Halperin; e A epistemologia do armário, de Eve Kosofsky. Dessa forma, Miskolci enfatiza as construções sociais e históricas em torno da homossexualidade, bem como da heterossexualidade.

No segundo capítulo, "Estranhando a educação”, o autor inicia pontuando que a educação teve uma receptividade e positividade quanto à teoria queer no Brasil, como mostram os trabalhos de Guacira Lopes Louro, em virtude da sensibilidade de educadores e educadoras sobre as normas sociais que impõem padrões de comportamento e de identidade. "Nossa recepção se deu por meio da ênfase de pesquisadores ingleses na 'experiência' das pessoas do povo, na valorização de empreendimentos históricos e sociológicos que recontassem a história oficial sob sua perspectiva” (MISKOLCI, 2012, p. 36).

Visando incorporar o queer na educação, é enfatizada a busca de um diálogo crítico e não assimilacionista com aqueles que são desvalorizados no processo educativo, o que pode mudar a perspectiva da educação e da escola, uma vez que o processo de normalização é intensificado nesses âmbitos: por exemplo, o bullying sempre esteve presente no processo educacional.

\footnotetext{
A escola era partícipe do assédio moral de tal forma que, normalmente, a educação era bullying: você entrava e se enquadrava. Havia um currículo oculto, um processo não dito, não explicitado, não colocado nos textos, mas que estava na própria estrutura do aprendizado, nas relações interpessoais, até na própria estrutura arquitetônica, que continua a ser normalizadora. (MISKOLCl, 2012, p. 38)
}

Segundo o autor é na sexualidade, pensando nela de forma ampla como desejo, afeto, autocompreensão, imagem e intimidade, que a sociedade encontra um poderoso meio de normalização, ao transformar essa sensação em motivo de chacotas, xingamentos, ofensas e humilhações. Logo, a abjeção acaba sendo maior em torno da sexualidade. Abjeção compreendida como horror, repulsa, impureza, algo que se tiver contato pode lhe contaminar.

Em tal contexto, Miskolci discute como a heteronormatividade está presente nos processos sociais e educacionais e busca diferenciá-la dos conceitos de heterossexismo e heterossexualidade compulsória. O heterossexismo é o pressuposto de que todas as pessoas são ou deveriam ser heterossexuais. A heterossexualidade compulsória é a determinação 
de um modelo de relacionamentos amorosos e sexuais sempre entre pessoas de sexos diferentes geralmente expressa indiretamente, como nos livros escolares e na mídia. Já a heteronormatividade "é a ordem sexual do presente fundada no modelo heterossexual, familiar e reprodutivo. Ela se impõe por meio de violências simbólicas e físicas dirigidas principalmente a quem rompe normas de gênero" (MISKOLCI, 2012, p. 44).

Assim, o autor ressalta que muito do conhecimento científico não é neutro, sendo produzido nessa perspectiva heterossexista. Então, ele defende a distinção da educação voltada para a diversidade e para a diferença. O termo diversidade refere-se à diferença como algo a ser tolerado, buscando reconhecer o direito de minorias em um contexto institucional universalista. Ainda, a diversidade se liga ao multiculturalismo com o "cada um no seu quadrado", o que contribui para manter as relações de poder intocadas. Já no caso da diferença, busca-se a transformação, a mudança das relações de poder, uma vez que tolerar é diferente de reconhecer o outro e de valorizá-lo em sua particularidade.

Daí a perspectiva não normativa de Educação mostrar que a experiência da abjeção não diz respeito apenas a quem foi qualificado de anormal, estranho, mas constitui quem nós somos e muito frequentemente o que a sociedade nos fez crer que é o que há de pior em nós [...] Talvez, espero, tenhamos começado a reavaliar isso, e, ao invés de educar para homogeneizar ou alocar confortavelmente cada um em uma gaveta, estejamos começando a aprender a nos transformar por meio das diferenças. (MISKOLCI, 2012, p. 49)

No último capítulo, "Um aprendizado pelas diferenças", Miskolci destaca as possibilidades e os desafios de uma educação não normalizadora:

O grande desafio na educação talvez permaneça o mesmo: o de repensar o que é educar, como educa e para que educar. Em uma perspectiva não normalizadora, educar seria uma atividade dialógica em que as experiências até hoje invisibilizadas, não reconhecidas, ou mais comumente, violentadas, passem a ser incorporadas no cotidiano escolar, modificando a hierarquia entre quem educa e quem é educado e buscando estabelecer mais simetria entre eles de forma a se passar da educação para um aprendizado relacional e transformador para ambos. (MISKOLCI, 2012, p. 51)

Desse modo, o autor defende uma educação que não seja uma normalização para o Estado, mas sim um veículo de desconstrução de desigualdades e injustiças, indo além da escola e abrangendo toda a 
sociedade. Para ele, materiais e livros escolares deveriam ser utilizados como forma de reflexão e questionamento, em que os desenhos, por exemplo, se aproximem das intersecções de diferenças de cada estudante. A nossa escola foi muito influenciada por um ideal europeu, renegando muitas vezes questões tocantes às culturas indígena e africana.

É ressaltada, também, a importância de se questionar a heteronormatividade presente nos currículos escolares, mas, além disso, devemos questionar os próprios binários que, na verdade, restringem as diversas e múltiplas expressões afetivas e sexuais. Desse modo, a pauta queer busca o reconhecimento sem assimilação, a resistência aos modelos hegemônicos: "em síntese, ao invés de ensinar e reproduzir a experiência da abjeção, o processo de aprendizado pode ser de ressignificação do estranho, do anormal como veículo de mudança social e abertura para o futuro" (MISKOLCI, 2012, p. 63).

Destacam-se dois pontos positivos do livro: o primeiro refere-se à teoria queer em si, que é abordada de forma clara, pontual e instigante pelo autor, o que demonstra seu domínio intelectual, teórico e reflexivo sobre a mesma, possibilitando que o livro também seja utilizado como um guia inicial para aqueles que querem aprender sobre essa teoria, tendo em vista a gama de conceitos apresentados; o outro ponto faz referência à proposta de problematizar uma educação não normalizadora e que exalte as diferenças em prol da igualdade e da não violência, proposta que ainda é um desafio atual e relevante na sociedade e na esfera da educação.

\section{HENRIQUE LUIZ CAPRONI NETO}

Mestrando em Administração com ênfase em Estudos Organizacionais e Sociedade pela Universidade Federal de Minas Gerais - UFMG -,

Belo Horizonte, Minas Gerais, Brasil

henriquecap_adm@yahoo.com.br 